\title{
The Major Delayed Rectifier in Both Drosophila Neurons and Muscle Is Encoded by Shab
}

\author{
Susan Tsunoda' ${ }^{1}$ and Lawrence Salkoff ${ }^{1,2}$ \\ 'Department of Anatomy and Neurobiology and 'Department of Genetics, Washington University School of \\ Medicine, St. Louis, Missouri 63110
}

\begin{abstract}
The delayed rectifier $\mathbf{K}^{+}$current in Drosophila is similar to the classical delayed rectifier, originally described by Hodgkin and Huxley. Drosophila provides unique tools of mutant analysis to unambiguously determine the genetic identity of this native $\mathrm{K}^{+}$current. We identified the Shab gene as the exclusive gene underlying delayed rectifier currents in both muscle and neurons. In muscles, a genetic mutation of Shab removes virtually all the whole cell delayed rectifier current $\left(I_{k}\right)$, while leaving unaltered the transient A-current encoded by the Shaker gene. In neurons, the Shab mutation also removes the bulk of $l_{\mathrm{k}}$, but leaves unaltered the transient A-current encoded by the Shal gene. Although most of the delayed rectifier current is the product of the Shab gene, the Shaw gene contributes a small "leak" current to most neurons and muscle cells. Thus, in contrast to the A-currents which are encoded by different genes in muscle and neuronal cell bodies (Shaker and Shal, respectively), the predominant $l_{\mathrm{K}}$ in both muscle and neurons is encoded by the same gene (Shab). With the genetic identity of $l_{K}$ confirmed, all of the major $K$ currents in embryonic Drosophila neurons and muscle are now known.
\end{abstract}

[Key words: Drosophila, potassium channels, mutant analysis, Shaker, Shal, Shab, Shaw, embryonic neurons, excitable membranes, $\mathrm{I}_{K}$, delayed rectifier, mutant]

The total voltage-dependent outward $\mathrm{K}^{+}$current in most neurons and muscles can loosely be divided into two components, a rapidly inactivating A-type current, $I_{\mathrm{A}}$, and a much more slowly inactivating "delayed rectifier" (DR) component, $I_{\mathrm{K}}$. These two components were originally identificd as separable components based on pharmacology (Thompson, 1982). 4-Aminopyridine (4AP) was found to rather selectively block $I_{\mathrm{A}}$, while tetraethylammonium (TEA) preferentially blocks $I_{\mathrm{K}}$. In Drosophila flight muscle, the genetic, developmental, and functional independence of these two components became obvious when they were examined at different stages of development in wild type and Shaker mutant flies. Shaker mutations remove $I_{\mathrm{A}}$ in Drosophila flight

\footnotetext{
Received Feb. 9, 1995; accepted Mar. 2, 1995.

We thank Dr. Arthur D. Wohlwill for the deficiency fly stock used in this study. We also thank J. Ray, Dr. M. Saito, M. Schreiber, and Dr. A. Wei for comments and suggestions on this manuscript. This study was supported by grants from the National Institute of Health, Muscular Dystrophy Association, and Monsanto.

Correspondence should be addressed to Lawrence Salkoff, Department of Genetics, Washington University School of Medicine, Box 8108, 660 South Euclid Avenue, St. Louis, MO 63110.

Copyright (C) 1995 Society for Neuroscience $0270-6474 / 95 / 155209-13 \$ 05.00 / 0$
}

muscles, but not $I_{\mathrm{K}}$ (Salkoff and Wyman, 1981; Salkoff, 1983, 1985; Wu and Haugland, 1985; Solc et al., 1987; Zagotta et al., 1988; Broadie and Bate, 1993). Thus, $I_{\mathrm{A}}$ and $I_{\mathrm{K}}$ were shown to be genetically independent in muscles. $I_{\mathrm{A}}$ and $I_{\mathrm{K}}$ were also shown to be genetically independent in Drosophila neurons by a mutation of the Shal gene which eliminates $I_{\mathrm{A}}$ in neurons (Tsunoda and Salkoff, 1995), but leaves $I_{\mathrm{K}}$ unaltered.

$I_{\mathrm{A}}$ and $I_{\mathrm{K}}$ in muscle were also shown to have distinct developmental profiles: $I_{\mathrm{A}}$ appears first, reaching maturation $72 \mathrm{hr}$ after pupariation, while $I_{\mathrm{K}}$ appears second, reaching maturation $96 \mathrm{hr}$ after pupariation (Salkoff, 1985). $I_{\mathrm{A}}$ and $I_{\mathrm{K}}$ also appear on a similarly staggered developmental schedule in some vertebrate neurons such as quail chick neurons (Bader et al., 1985). Functionally, $I_{\mathrm{A}}$ and $I_{\mathrm{K}}$ also play different roles in Drosophila flight muscles, with $I_{\mathrm{A}}$ responsible for very rapid repolarization of the action potential, and $I_{\mathrm{K}}$ responsible for a slower phase of repolarization (Salkoff, 1985).

While the $I_{\mathrm{A}}$ currents in muscle and neurons have been genetically identified (Shaker and Shal), $I_{\mathrm{K}}$ currents in both cell types have not previously been genetically identified. Of the four cloned voltage-dependent $\mathrm{K}^{+}$channel genes, Shaker, Shal, Shab, and Shaw, $I_{\mathrm{K}}$ was most likely encoded by Shab and/or Shaw, because both express DR type currents in the Xenopus oocyte expression system (Wei et al., 1990). Because Shab currents heterologously expressed in Xenopus oocytes were the most similar to $I_{\mathrm{K}}$ in neurons and muscle cells, we suspected $S h a b$ to be a major contributor to $I_{\mathrm{K}}$. To test this hypothesis, we cxamined neurons and muscle cells which are mutant for the Shab gene. We found that indeed virtually all of $I_{\mathrm{K}}$ was eliminated by a mutation of the $S h a b$ gene, thus showing that $S h a b$ does encode the predominant DR current component in both neurons and muscle cells.

In contrast to the other voltage-dependent $\mathrm{K}^{+}$channel genes, Shab appears to be a major contributor to the whole cell current in both neurons and muscle. Shab $\mathrm{K}^{+}$channel genes in mammals (Frech et al., 1989; Pak et al., 1991) are also expressed in a wide variety of tissues, including brain, heart, skeletal muscle, and many of the sensory systems (Trimmer, 1991; Hwang et al., 1992; Hwang et al., 1993a,b; Trimmer, 1993). Our study differs from the studies in mammalian systems in that it proved feasible to genetically delete the Shab gene in Drosophila. This enabled us to observe the remaining DR currents present after Shab removal. Our striking result is that there appears to be no other major DR current present in Drosophila.

\section{Materials and Methods}

\section{Cell culture}

Late-gastrula cell cultures were prepared in a manner similar to previous reports (Seecof et al., 1971; Tsunoda and Salkoff, 1995). Eggs were 


\section{Experiment}

\section{Control}

WT Df

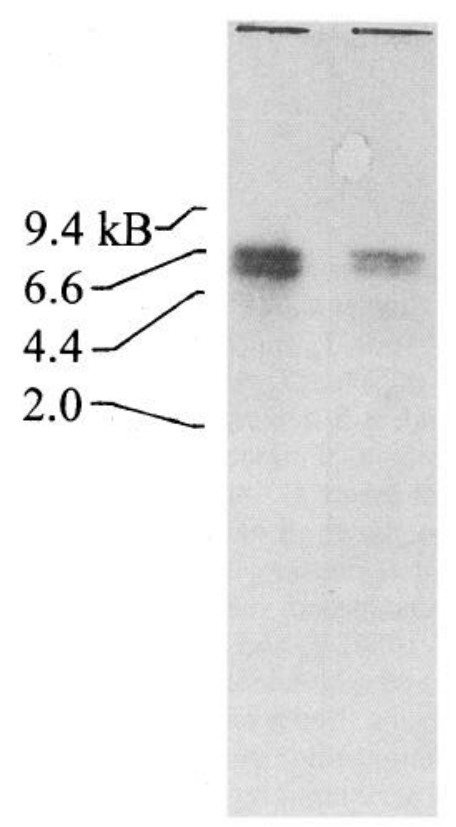

WT Df

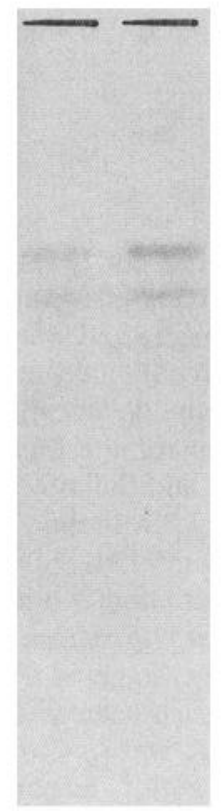

Experiment

\section{Control}

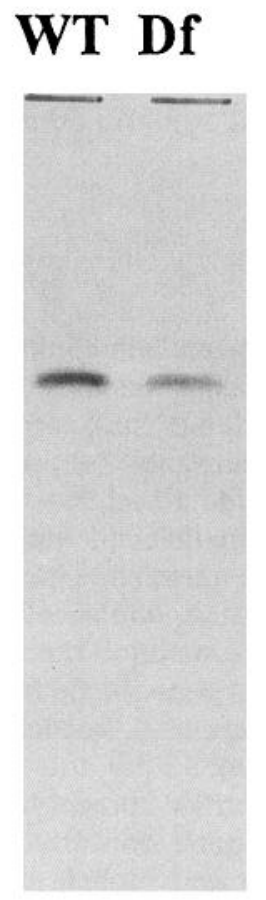

WT Df

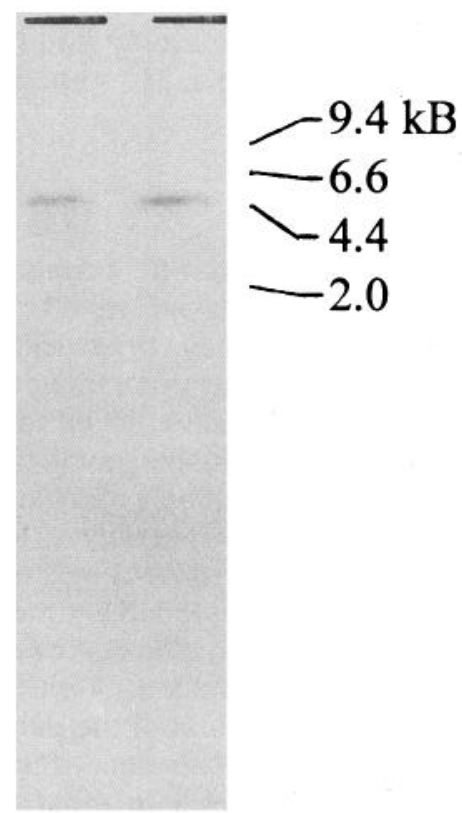

Figure 1. Southern analysis confirms that the Shab gene falls within the deficiency. Genomic DNAs from wild type (WT) and heterozygous deficiency, $\mathrm{Df}(3 \mathrm{~L}) \mathrm{HR} 370+\mathrm{Dp}(3 ; 3)$ pdp7/TM3 ftz-lacZ, (Df) flies were cut with EcoRI (left pair), and SalI (right pair). Experiment, Southern blots probed with the cDNA of the Shab gene; Control, same blots later probed with a control gene (see Materials and Methods). Labeled bands were quantified (see Materials and Methods). Bands labeled with the Shab cDNA were normalized to the intensity of bands labeled with a control gene. Heterozygous deficiency bands were 50\% (EcoRI) and 67\% (SalI) of wild type control. We expect DNA of the heterozygous deletion flies to label with an average intensity of $50 \%$ of the wild type control DNA.

collected over a $1-2 \mathrm{hr}$ period and allowed to develop in a humidified chamber at room temperature for about 5.5-6 hr for neuronal recordings, and 7-8 hr for myotube recordings. Eggs were rinsed with $70 \%$ ethanol, dechorionated by rolling on double-stick Scotch tape, and covered with halocarbon oil. A sharp microelectrode was used to break through the vitellin membrane of single embryos and all contents were removed by suction. Single embryos were dissociated into a $20 \mu \mathrm{l}$ drop of culture media similar to media previously described (Seecof and Donady, 1972): $18 \%$ fetal calf serum, $6 \mathrm{mU} / \mathrm{ml}$ insulin, $1 \%$ penicillinstreptomycin (from a stock of $10 \mathrm{kU}$ penicillin and $0.5 \mathrm{mg} / \mathrm{ml}$ streptomycin in $0.9 \% \mathrm{NaCl}$ ), in Schneider's Medium. Cultures were prepared on glass coverslips. Cultures were grown at room temperature in a humidified chamber for $20-72 \mathrm{hr}$ before being used for electrophysiology.

\section{Fly stocks}

(1) Wild type flies: Oregon-R strain.

(2) Shaker mutants: Sh ${ }^{102}$ flies. Molecular analysis of this mutation revealed a nonsense mutation closing the open reading frame between the S5 and S6 transmembrane spanning domains (Gisselmann et al., 1989).

(3) Shab mutants: a genetic deficiency, $D f(3 L) H R 370+D p(3 ; 3) p d p 7$. This chromosome has a net deficiency of 63A to 63B8-9 (courtesy of Dr. Arthur D. Wohlwill; Wohlwill and Bonner, 1991). Shab was mapped to chromosomal band $63 \mathrm{~A}$ on the left arm of the third chromosome (Butler et al., 1989). The deficiency, Df(3L)HR370, from 63A to 63D, combined with the duplication, $\mathrm{Dp}(3 ; 3)$ pdp7, from 63B8-9 to 65 (Wohlwill and Bonner, 1991) results in a net deficiency of 63A to 63B8-9 which encompasses the Shab locus. We confirmed that Shab falls within this deficiency by genomic Southern analysis (Fig. 1). The Shab deficiency was maintained over a third chromosome balancer (either TM3 or TM6B) which carried the lac $Z$ gene driven by the $f t z$ promoter, which was essential for determining the genotype of a given culture.

(4) Shal mutants: a genetic deficiency, $D f(3 L) J K 18$ or $D f(3 L) k t o 2$ (Lindsley and Zimm, 1992). This deficiency was shown to eliminate the transient Shal A-currents in neurons (Tsunoda and Salkoff, 1995).

\section{Identifying neurons and myotubes}

Although whole embryos containing many different cell types are dissociated, culture conditions have been shown to favor the survival of mainly muscle cells and neurons (Shields and Sang, 1970; Seecof et al., 1971). We identified cells which stained positive with FITC-conjugated anti-horseradish peroxidase (anti-HRP) (data not shown), an antibody which specifically recognizes CNS and PNS neurons in Drosophila (Jan and Jan, 1982). Positively staining neurons were cells with round cell bodies, $5-8 \mu \mathrm{m}$ in diameter, and extended processes. These cells grew either singly or in clusters in culture and no difference in physiology was unique to single or clustered cells. Because of their distinct morphology, neurons could be reliably selected for electrophysiology in unstained cultures.

Myotubes were also identified by morphology for electrophysiology. These cells were observed to contract in culture. In addition, when cells from a strain containing the lac $Z$ gene driven by the myosin heavy chain promoter, which has muscle specific expression, were stained with $\mathrm{X}$-gal, myotubes like the ones chosen for electrophysiology stained blue.

\section{Fixing and staining cultures}

After recording, cells were immediately fixed for $2-4 \mathrm{~min}$ in $2 \%$ formaldehyde, $0.4 \%$ glutaraldehyde, in phosphate buffer solution (PBS). 
A) Wild Type

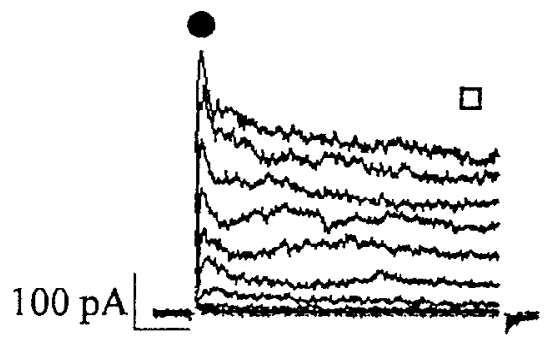

$15 \mathrm{~ms}$

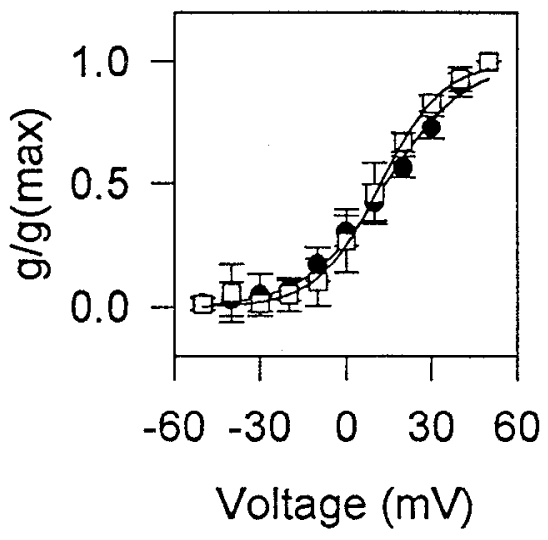

D)
B) Shaker Mutant
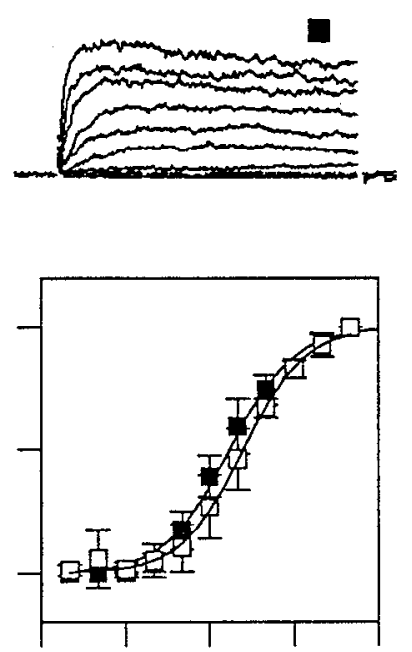

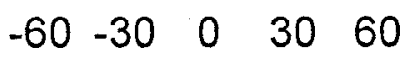

Voltage $(\mathrm{mV})$
C) Shab Mutant
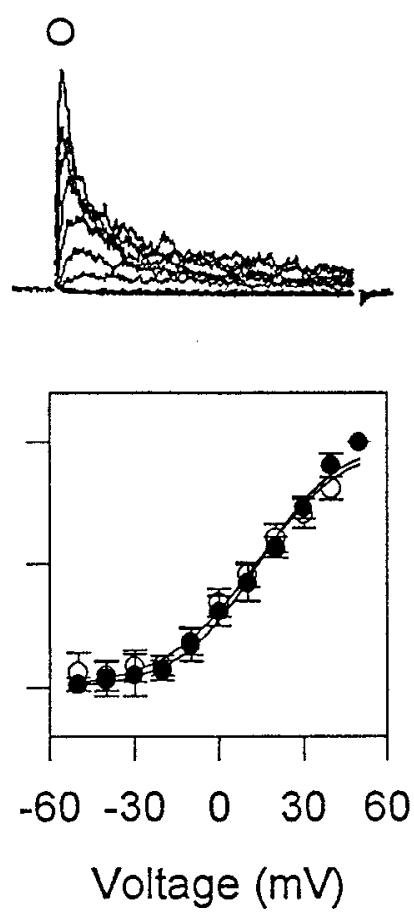

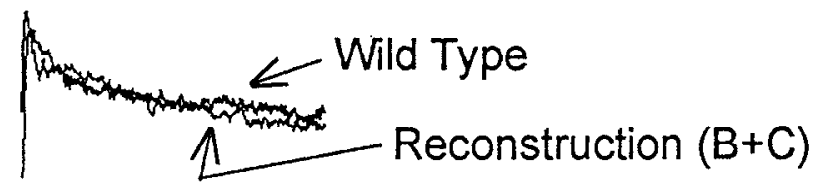

Figure 2. Shab Mutation Removes $I_{\mathrm{K}}$ in Myotubes. A, Representative whole cell currents from a wild type myotube. The steady-state component, measured $80 \mathrm{msec}$ after jump onset, was $69.10 \pm 10.17 \%$ of the total peak current $(N=13)$. Conductance-voltage relations $(N=5$ cells $)$ of peak current $(\bigcirc)$ and steady-state current $(\square)$ are shown below. SDs are indicated. A single Boltzmann equation, $g / g_{\max }=1 /\left(1+\exp \left(\left(V-V_{15}\right) / k\right.\right.$ was fit to each curve, where $g / g_{\max }$ is the normalized conductance, $V_{1 / 2}$ is the voltage at which $g / g_{\max }$ is half-maximal, and $k=R T / z F$. Best fit parameters are as follows: for peak current, $V_{1 / 2}=13.75 \pm 1.03 \mathrm{mV}, z=1.81 \pm 0.11 \mathrm{mV} / e$-fold shift; for steady-state current, $V_{1 / 2}=11.92 \pm 0.56 \mathrm{mV}, z=$ $2.31 \pm 0.10 \mathrm{mV} / e$-fold shift. $B$, Representative whole cell current, $I_{\mathrm{K}}$, in a Sh ${ }^{102}$ myotube where the Shaker current $\left(I_{\mathrm{A}}\right)$ is removed. Below, conductance-voltage relation ( $\square, N=7$ ) of $I_{\mathrm{K}}$ in Shaker ${ }^{102}$ myotubes superimposed on the conductance-voltage relation of the steady-state current in wild type myotubes from $A(\square) . g / g_{\max }$ is plotted versus voltage and fit with a Boltzmann equation as described in $A$. Best fit parameters are $V_{1 / 2}$ $=6.9 \pm 0.87 \mathrm{mV}, z=2.22 \pm 0.14 \mathrm{mV} / e$-fold shift. $C$. Representative whole cell currents from Shab-deficient myotubes $(N=13)$. Most of the steady-state component was removed with only an estimated $23 \%$ remaining. This was only $15.59 \pm 7.35 \%$ of the total peak current. Conductancevoltage relation of the transient Shaker current remaining in Shab-deficient myotubes is shown below $(N=6)(O)$ and is compared to the conductance-voltage relation of the peak current in wild type myotubes in $A(\mathbf{O})$. Best fit parameters to Boltzmann equation are $V_{1 / 2}=12.82 \pm$ $1.28 \mathrm{mV}, z=1.57 \pm 0.11 \mathrm{mV} / e$-fold shift. $D$, Whole cell currents at $+50 \mathrm{mV}$ reconstructed from a linear combination of Shaker mutant and $S h a b$-deficient current traces are superimposed on a wild type current for comparison. Voltage jumps $(80 \mathrm{msec})$ were from -50 to $+50 \mathrm{mV}$ in 10 $\mathrm{mV}$ increments from a holding potential of $-90 \mathrm{mV}$. Whole cell conductance $(g)$ was calculated from the equation $g=I /\left(V-E_{r}\right)$, where $I$ is peak current elicited by voltage jumps to different test potentials, $V$ is membrane potential, and $E_{r}$ is the reversal potential for this current. $E_{r}$ was calculated to be $-84 \mathrm{mV}$ from the Goldman-Hodgkin-Katz current equation, assuming that $P_{\mathrm{Na}} / P_{\mathrm{K}}=0.03$ (Hille, 1992) and the solutions used. $g / g_{\max }$ values plotted are the averages, at each potential, of the normalized conductance for each cell.

Cultures were rinsed with PBS after fixing and stained overnight at $30^{\circ} \mathrm{C}$ with an X-gal solution containing: $1 \mathrm{mg} / \mathrm{ml} \mathrm{X-gal} \mathrm{(from} \mathrm{a} 8 \%$ stock made up in DMSO), $16 \mathrm{~mm}$ KFerrocyanide, $16 \mathrm{~mm}$ KFerricyanide, 2 $\mathrm{mM} \mathrm{MgCl}_{2}$ in PBS, $\mathrm{pH} 7.2-7.3$. Cultures were rinsed with PBS and checked for blue staining.

\section{Determining the genotype of a given culture}

The following strategy was used to determine which single-embryo cultures were homozygous deficient for the Shab gene. The Shab deficien$c y$ is maintained over a balancer chromosome containing the lac $Z$ gene. 
Table 1. Comparison of $I_{\mathrm{K}}$ in muscle and neurons

\begin{tabular}{lrr}
\multicolumn{1}{l}{ Muscle } & \multicolumn{1}{c}{ Neuron } \\
\hline $\begin{array}{l}\text { Activation } \\
V_{\mathrm{t} / 2}\end{array}$ & $7 \pm 0.9$ & $-1 \pm 1.2$ \\
$z$ & $2 \pm 0.1$ & $2 \pm 0.1$ \\
Steady-state inactivation & & \\
$\quad V_{\mathrm{V} / 2}$ & $-27 \pm 0.4$ & $-30 \pm 0.3$ \\
$z$ & $7 \pm 0.9$ & $4 \pm 0.2$ \\
Time to $90 \%$ maximum current & & \\
$\quad$ at $+50 \mathrm{mV}$ & $15 \pm 1.2$ & $14 \pm 1.1$ \\
at $+10 \mathrm{mV}$ & $31 \pm 7.2$ & $20 \pm 5.3$
\end{tabular}

Properties of the $I_{\mathrm{K}}$ current in muscle were examined in Shaker mutant myotubes, while those in neurons were examined in wild type neurons which were subjected to a (500 msec) prepulse to $-50 \mathrm{mV}$ in order to inactivate the $I_{\mathrm{A}}$ (Shal) current present. $N=7$ for muscle activation curves; $N=6$ for neuron activation curves; $N=5$ for muscle steady-state inactivation curves; $N=9$ for neuron steady-state inactivation curves; $N=6$ for all time to $90 \%$ maximum current measurements. Averages are shown with standard deviations as noted.

The intercross of heterozygous $S h a b$-deficient flies produce three genotypes in a 1:2:1 ratio: one-quarter homozygous for the balancer chromosome, one-half heterozygous, and one-quarter homozygous Shab deficiency. Cells homozygous and heterozygous for a balancer chromosome will synthesize $\beta$-galactosidase and stain blue when treated with $\mathrm{X}$-gal. Only embryos homozygous for the deficiency will not stain.

\section{Electrophysiology}

The patch-clamp technique was used to record whole cell currents (Hamill et al., 1981). Electrodes were pulled using borosilicate glass and had resistances of about $20 \mathrm{M} \Omega$ in solutions used (below). Electrodes were Sylgarded for single channel recordings. Although series resistance errors affect the exactness of the voltages reported (such as in conductance-voltage relations), they do not affect the assays for currents used in these mutant analyses. Measured series resistance, $27 \mathrm{M} \Omega$ on average for neurons and $16 \mathrm{M} \Omega$ for myotubes, was $90 \%$ compensated (except for mutant data in Figs. 3 and 4, which were uncompensated). Uncompensated series resistance remaining, assuming a true series resistance of twice that of the electrode resistance (Marty and Neher, 1983 ) is about $16 \mathrm{M} \Omega$ for neurons and $26 \mathrm{M} \Omega$ for myotubes. Whole cell recordings which were digitized at $0.097 \mathrm{msec} / \mathrm{pt}$ for voltage jumps $80 \mathrm{msec}$ in duration, and $0.488 \mathrm{msec} / \mathrm{pt}$ for voltage jumps $480 \mathrm{msec}$ in duration. Whole cell recordings were lowpass filtered through an $80 \mathrm{~dB}$ Bessel filter with a cutoff frequency of $2 \mathrm{kHz}$.

Data was acquired using an Axopatch $200 \mathrm{~A}$ amplifier (Axon Instruments). Data acquisition software used was CCURRENT (Dr. Keith Baker; Indec, Sunnyvale, CA). Analysis software included CQUANT (Dr. Keith Baker), NFIT (University of Texas, Galveston, TX), QPRo (Borland International, Inc., Scotts Valley, CA), and sIGMAPLOT (Jandel Scientific, Corte Madera, CA).

Solutions (in mM): internal, $140 \mathrm{~K}$-gluconate, $2 \mathrm{MgCl}_{2}, 11$ EGTA, 10 HEPES; external, $140 \mathrm{Na-gluconate,} 2 \mathrm{~K}$-gluconate, $6 \mathrm{Mg}$-gluconate $_{2}, 5$ HEPES, 5 trehalose, 20-35 sucrose (to adjust osmolarity), and $100 \mathrm{nM}$ tetrodotoxin. Some recordings were performed with aspartate as the major anion instead of gluconate; both anions gave similar results.

\section{Southern analysis}

Shab was confirmed to fall within the deletion, Df(3L)HR$370+\mathrm{Dp}(3 ; 3) \mathrm{pdp} 7$ by Southern analysis (Fig. 1). Genomic DNA from wild type (OR-R) and heterozygous Df(3L)HR370 + Dp(3;3)pdp7/TM3 ftz-lacZ flies was isolated by homogenization of whole adult flies in $0.1 \%$ SDS in TE, followed by phenol/chloroform extractions and DNA precipitation; $3 \mu \mathrm{g}$ of DNA was digested with restriction enzyme Eco RI, SacI, or SalI, and then run on a $1 \%$ agarose gel (EcoRI or SacI) or $0.7 \%$ agarose gel (SalI). DNA fragments were transferred to nitrocellulose and probed at high stringency with a fragment of the Shabll cDNA, encompassing S1 to S6 core region of the channel. Quantitation of DNA in each band was performed using a Phospholmager (Molecular Dynamics, Inc.) and associated software called IMAGEQUANT. For the heterozygous deletion stock it was expected that restriction fragments labeled with a $S h a b$ specific probe would be half the intensity of control bands for genes present in two doses. Hence, to normalize quantitation for the amount of DNA in each lane, blots were later probed with the cDNA of the Shal gene (for cuts with EcoRI or SacI), or probed with the cDNA, 3-1AL, of the Drosophila $\mathrm{Na}^{+}$channel gene (for cuts with SalI). In the DNA containing the heterozygous deficiency of Shab, the labeled band indicating the single copy of Shab was quantified and determined to be half the intensity of a diploid control band (Fig. 1).

\section{Results}

\section{Currents in embryonic muscle}

Muscle from all stages of Drosophila, including pupal flight muscle, larval body wall muscle, and embryonic myotubes contain two separable voltage-dependent $\mathrm{K}^{+}$current components, $I_{\mathrm{A}}$ and $I_{\mathrm{K}}$ (Salkoff and Wyman, 1981; Salkoff, 1983; Wu and Haugland, 1985; Zagotta et al., 1988; Broadie and Bate, 1993). Muscle cells examined in this study are dissociated from $7 \mathrm{hr}$ embryos, and allowed to develop in culture for up to $48 \mathrm{hr}$. Since the development from embryo to first instar larvae is normally complete in $24 \mathrm{hr}$, the cells used in this study probably correspond to the body wall muscles of the larvae.

$I_{\mathrm{A}}$ in pupal, larval, and embryonic muscle has been genetically identified as Shaker (Salkoff and Wyman, 1981; Salkoff, 1983; Wu and Haugland, 1985; Solc et al., 1987; Zagotta et al., 1988; Broadie and Bate, 1993), as well as $I_{\mathrm{A}}$ in Drosophila photoreceptors (Hardie et al., 1991). However, $I_{K}$ was not identified in these previous studies. Under voltage clamp, both $I_{\mathrm{A}}$ and $I_{\mathrm{K}}$ current components are evident in wild type myotubes subjected to voltage jumps to depolarized potentials. Figure $2 A$ shows wild type whole cell currents which quickly reach a peak current that partially, but rapidly, inactivates to a steady-state current. The partially inactivating component corresponds to $I_{\mathrm{A}}$, while the steady-state current corresponds to $I_{\mathrm{K}}$. Figure $2 B$ shows removal of this component by a Shaker mutation. Figure $2 A$ (bottom) shows conductance-voltage relations of the two components, peak current, corresponding primarily to $I_{\mathrm{A}}$, and the steady-state current, corresponding to $I_{\mathrm{K}}$. Conductance-voltage relations are similar with respect to both range and slope. Both $I_{\mathrm{K}}$ and $I_{\mathrm{A}}$ activate around -30 to $-20 \mathrm{mV}$ and reach half-activation at 14 $\mathrm{mV}\left(I_{\mathrm{A}}\right)$ and $12 \mathrm{mV}\left(I_{\mathrm{K}}\right)(N=5)$.

\section{$\mathrm{I}_{K}$ in Shaker myotubes}

$I_{\mathrm{K}}$ is best separated from $I_{\mathrm{A}}$ using Shaker mutants which remove all the transient current from muscle. In Figure $2 B$ where $I_{\mathrm{A}}$ has been removed by a mutation of Shaker, $I_{\mathrm{K}}$ can be observed without any contamination from $I_{\mathrm{A}} . I_{\mathrm{K}}$ in Shaker mutant myotubes activates slowly around -30 to $-20 \mathrm{mV}$, with half-activation at about $+7 \mathrm{mV}(N=7$, Fig. $2 B$, bottom). Figure $2 B$, (bottom) shows conductance-voltage relations of $I_{\mathrm{K}}$ in Shaker mutant myotubes compared with that of $I_{\mathrm{K}}$ measured as the steady-state current in wild type myotubes. The similarity of the data shows that $I_{\mathrm{K}}$ is unaltered by the Shaker mutation. The steady-state inactivation properties of $I_{\mathrm{K}}$ in Shaker mutant cells suggested that $I_{\mathrm{K}}$ consists primarily of one DR component, because the data is fit well by a single Boltzmann (data not shown). However, frequently accompanying the $D R$, there is a much smaller noninactivating current component present in some cells. In the steady-state voltage paradigm used for these experiments, cells were prepulsed to different membrane potentials, and then stepped to the same test potential $(+50 \mathrm{mV})$. Steady-state inactivation curves are plotted as (normalized) peak current versus prepulse potential. In such experiments, data for the DR com- 


\section{A) Genetic Separation of $I_{K}$ and $I_{A}$.}

Wild Type

\section{Shal Mutant}
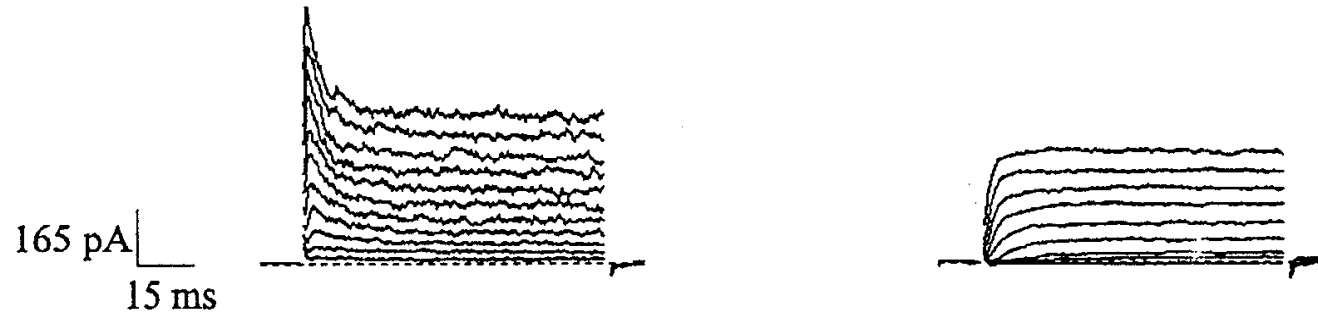

B) Separation of $I_{K}$ and $I_{A}$ by Steady-State Inactivation
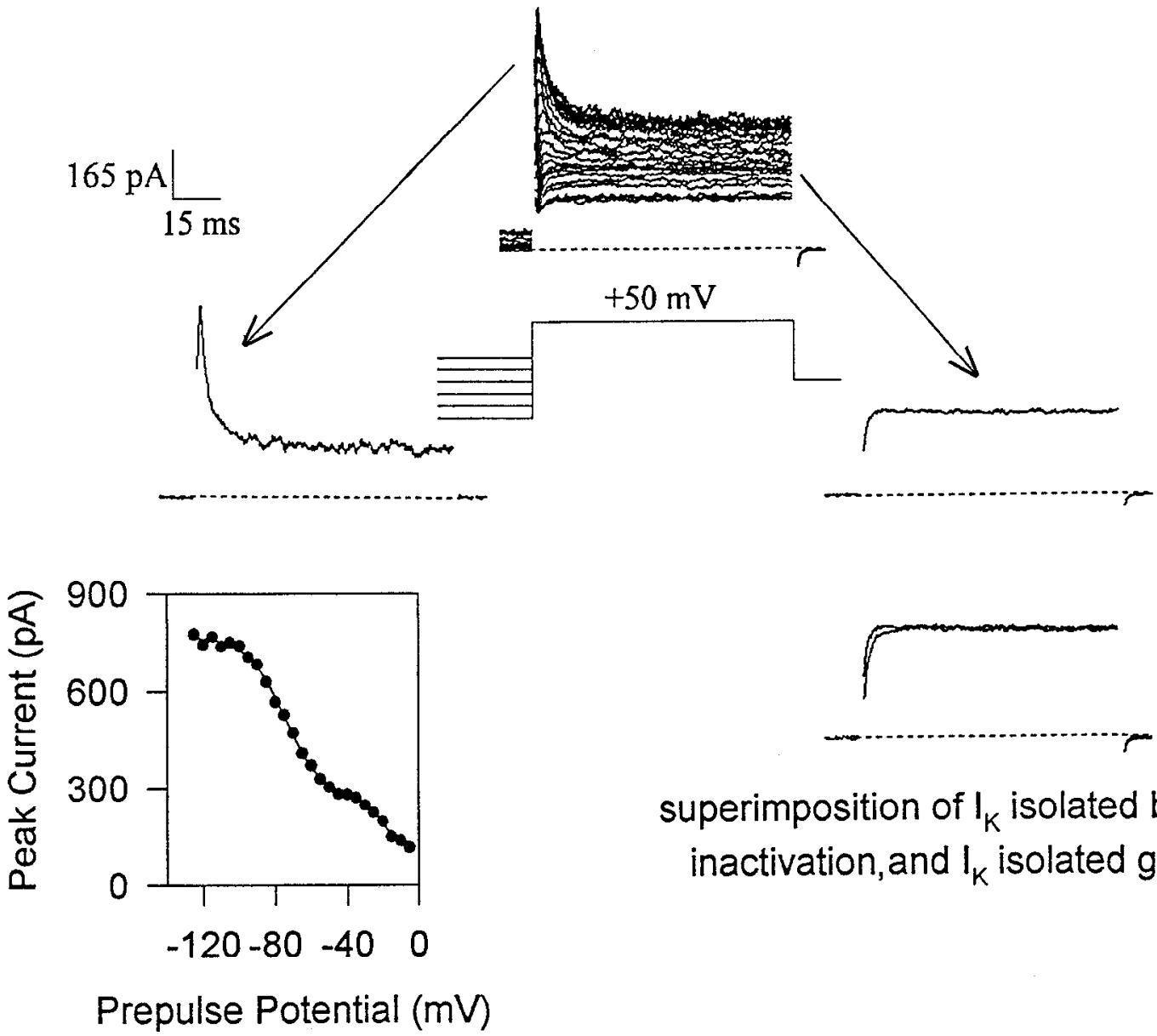

superimposition of $\mathrm{I}_{\mathrm{K}}$ isolated by prepulse inactivation, and $I_{K}$ isolated genetically

Figure 3. $I_{\mathrm{K}}$ separation from $I_{\mathrm{A}}$ in neurons: $A$, by genetics; $B$, by a physiological technique. $A$, Voltage dependent $\mathrm{K}^{+}$currents from a representative wild type (left) and Shal-deficient (right) neuron. Wild type currents consist of a transient Shal current as well as DR currents. In contrast, the Shal deficiency eliminates the transient Shal current and thus, reveals the DR currents present (right). B, Current traces in response to a steady-state inactivation voltage paradigm are shown from a representative wild type neuron (middle). Membrane was held (500 msec) at prepulse potentials from -125 to $-5 \mathrm{mV}$, in $5 \mathrm{mV}$ increments, before stepping to a test potential of $+50 \mathrm{mV}$. Bottom (left), peak current is plotted versus prepulse potential. Data points were fit with a double Boltzmann function $\left(I=I_{\max } /\left(1+\exp \left(\left(V-V_{1 / 2}\right) / k\right)\right)\right.$, indicating two separable components with distinct voltage-operating ranges. $I_{\mathrm{K}}$ is represented by the component with the more depolarized steady-state inactivation curve $\left(I_{\max }=147 \mathrm{pA}, V_{13}=-19.5\right.$ $\mathrm{mV}, z=5.07 \mathrm{mV} / e$-fold shift); the transient Shal current is representcd by the component with the morc hypcrpolarized stcady-state inactivation curve $\left(I_{\max }=510.8 \mathrm{pA}, V_{1 / 2}=-74.2 \mathrm{mV}, z=10.6 \mathrm{mV} / e\right.$-fold shift). Thus, the Shal current can be inactivated with a prepulse to $-45 \mathrm{mV}$, leaving primarily the DR current, $I_{\mathrm{K}}$ (top, right). Bottom (right), $I_{\mathrm{K}}$ isolated genetically in $A$ is superimposed on $I_{\mathrm{K}}$ isolated in $B$ with a prepulse to -45 $\mathrm{mV} . I_{\mathrm{K}}$ isolated by these independent methods are indistinguishable. 


\section{A) $I_{K}$ from Wild Type $\bullet \quad I_{K}$ from Shal Mutant $\square$}

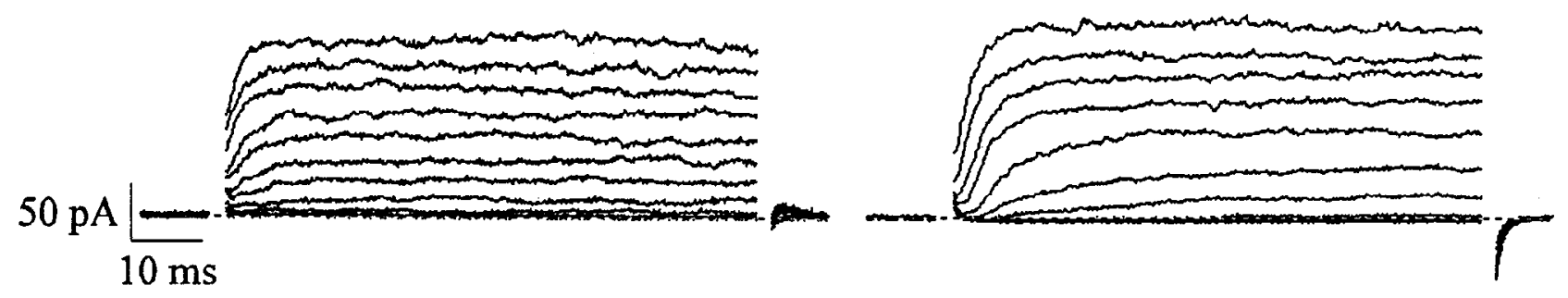

B) Activation

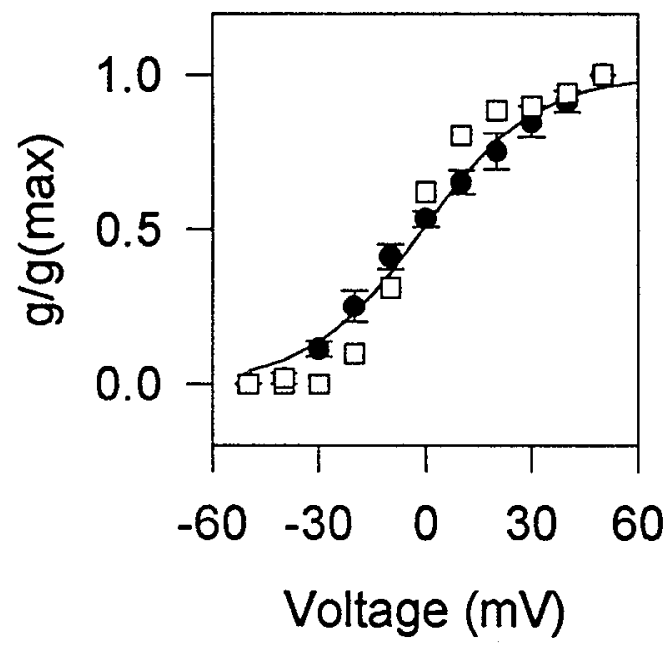

C) Steady-State Inactivation

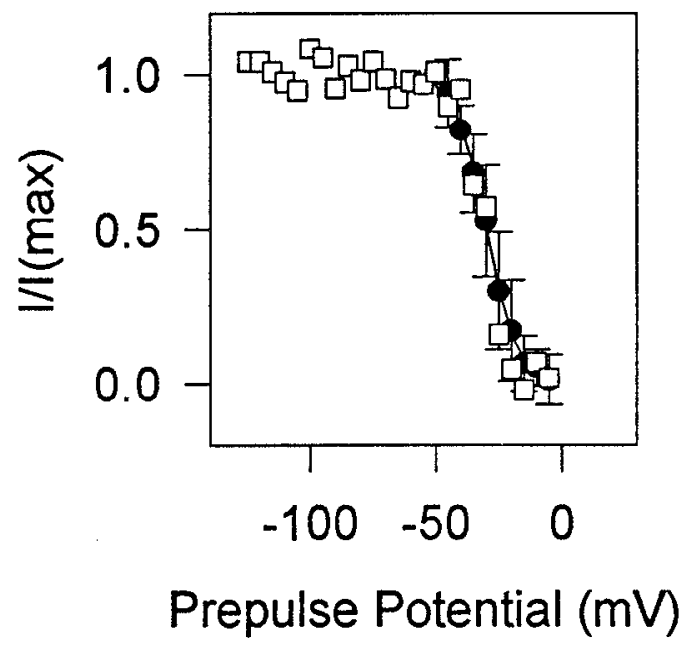

Figure 4. $I_{\mathrm{K}}$ in Shal mutant and wild type neurons. $A, I_{\mathrm{K}}$ remaining in a representative $S h a l$-deficient neuron (left) and $I_{\mathrm{K}}$ isolated in a wild type neuron with a $(500 \mathrm{msec})$ prepulse to $-50 \mathrm{mV}$ (right). Whole cell current traces are in response to 80 msec voltage jumps to potentials between $-50 \mathrm{mV}$ and $+50 \mathrm{mV}$, in $10 \mathrm{mV}$ increments. $B$, Conductance-voltage relations, and $C$, steady-state inactivation curves of $I_{\mathrm{K}}$ compared from wild type (O) and Shal-deficient neurons $(\square)\left(N=6\right.$ for activation; $N=9$ for steady-state inactivation). $I_{\mathrm{K}}$ is isolated from wild type by prepulse inactivation, and genetically in the Shal-deficient neuron. Conductance-voltage relations and steady-state inactivation curves are calculated, plotted, and fit with Boltzmann equation as described in Figure 2. Standard deviations are as indicated. Best fit parameters for conductance-voltage curve are $V_{1 / 2}=-1.05 \pm 1 / 20 \mathrm{mV}, z=1.59 \pm 0.10 \mathrm{mV} / e$-fold shift. Best fit parameters for steady-state inactivation curve are $V_{1 / 2}=-29.81 \pm 0.28$ $\mathrm{mV}, z=4.19 \pm 0.16 \mathrm{mV} / e$-fold shift.

ponent are fit with a single Boltzmann function (Fig. 2B), suggesting a single current component half-inactivated with a prepulse to $-27 \mathrm{mV}(N=5)$ (Table 1$)$.

Shab encodes the major delayed rectifier current in embryonic myotubes

We suspected that this major DR component is encoded by the Shab gene because it resembles Shab currents heterologously expressed in Xenopus oocytes. $I_{\mathrm{K}}$ currents, like Shab currents, are slowly inactivating and inactivate with prepulses to depolarized potentials (Wei et al., 1990). We investigated this hypothesis by performing mutant analysis, using a genetic mutation of the $S h a b$ gene (see Materials and Methods). To determine if Shab encodes $I_{\mathrm{K}}$ in embryonic myotubes, we characterized the component removed by the Shab mutation by comparing the DR currents in wild type myotubes to those in Shab-deficient myotubes. We first compared the amplitudes of $I_{\mathrm{K}}$ in wild type cells with $I_{\mathrm{K}}$ in the mutant. $I_{\mathrm{K}}$ was measured as the steady-state current remaining after $I_{\mathrm{A}}$ was inactivated $(80 \mathrm{msec})$. We found that the amplitude of $I_{\mathrm{K}}$ in wild type cells was, on average, $69 \%(N=$
13) of the peak $I_{\mathrm{A}}$ amplitude (Fig. 2A), but in Shab-deficient myotubes $I_{\mathrm{K}}$ was only $16 \%(N=13)$ of the peak $I_{\mathrm{A}}$ amplitude (Fig. $2 C$ ). Thus, the Shab deficiency eliminates $77 \%$ of the DR current in wild type myotubes. Figure $2 C$ shows the Shaker current remaining in Shab-deficient myotubes. Activation kinetics of the Shaker current are virtually identical to that of the peak $I_{\mathrm{A}}$ current in wild type myotubes (Fig. $2 C$, bottom), showing that $I_{\mathrm{A}}$ is unaltered by the Shab mutation. Figure $2 D$ verifies that the Shab or Shaker mutations eliminate only a selective component without altering the remaining currents in the cell. Thus, the linear addition of currents remaining in a Shaker mutant plus the currents remaining in a Shab mutant, reconstitutes the wild type whole cell current.

\section{Delayed rectifier currents in neurons}

Drosophila neurons, like muscle, contain both a transient A-type $\mathrm{K}^{+}$current component, $I_{\mathrm{A}}$, as well as a DR component, $I_{\mathrm{K}}$. In order to isolate and analyze $I_{\mathrm{K}}$ in neurons, two independent techniques were used, a genetic technique which is unique to Drosophila, and a more conventional physiological approach. The 

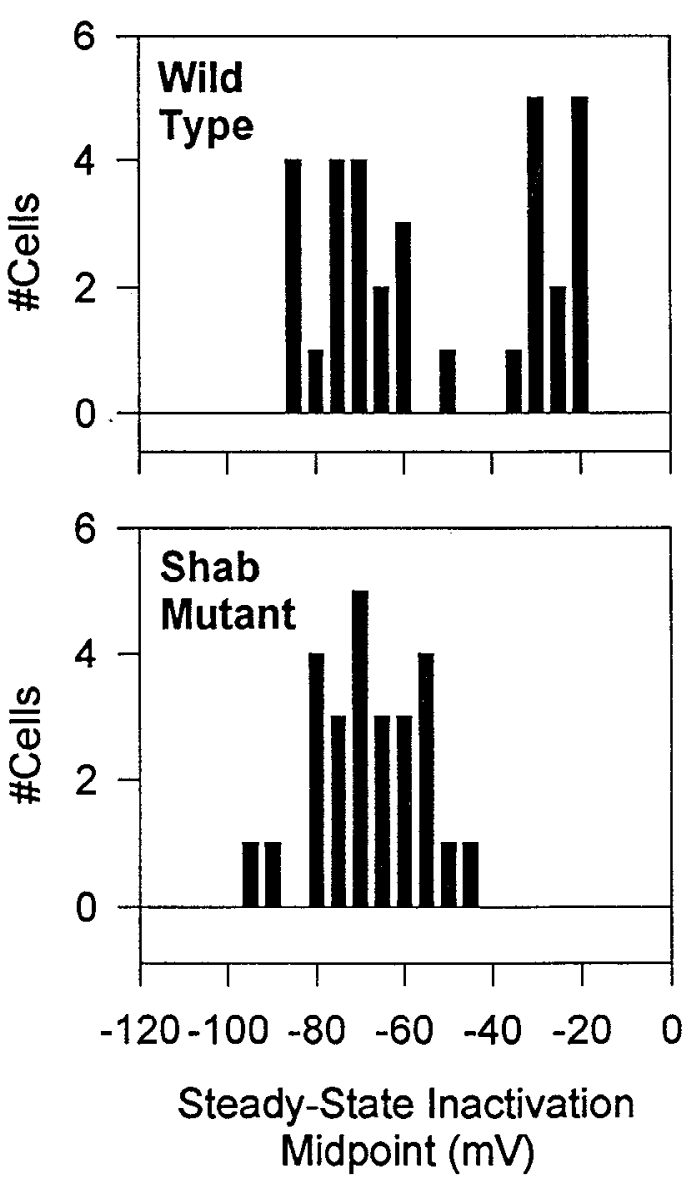

Figure 5. Distribution of steady-state inactivation midpoints in wild type and Shab mutant neurons. Wild Type, histogram of steady-state inactivation midpoints $\left(V_{32}\right)$ of current components in wild type neurons. Two populations of current components are evident in the wild type neurons $(N=18)$ : one population ( $g$ roup of bars to the left) has a more hypcrpolarized steady-state inactivation midpoint, averaging $-75 \pm 8.7$ $\mathrm{mV}$, and always corresponds to the transient Shal current component; another population (group of bars on the right) has a more depolarized steady-state inactivation midpoint, averaging $-29 \pm 8.0 \mathrm{mV}$, and always corresponds to a slowly inactivating current component, $I_{\mathrm{K}} .78 \%$ of wild type neurons contained these two separable components; $22 \%$ contained only the transient Shal current. Shab-Mutant, Histogram of steady-state inactivation midpoints $\left(V_{1 / 2}\right)$ of current components in Shabdeficient neurons. In contrast to the wild type neuron histogram, only one component remains in Shab-deficient neurons $(N=26)$. The population remaining in $S h a b$-deficient neurons corresponds to the transient Shal current components, having a more hyperpolarized steady-state inactivation midpoint of $-70.52 \pm 11.40 \mathrm{mV}$. The population of current components eliminated by the $S h a b$ deficiency corresponds to the slowly inactivating current $I_{\mathrm{K}}$ with a more depolarized steady-state inactivation midpoint. Steady-state inactivation midpoints $\left(V_{1 / 2}\right)$ of current components are determined from fits of single and double Boltzmann equations $\left(I=I_{\max } /\left(1+\exp \left(\left(V-V_{1 / 2}\right) / k\right)\right)\right)$ to data points representing peak current versus prepulse potentials. Voltage paradigm used and representative fits to data points are shown and described in Figures 6 and 7.

genetic technique employs a genetic deletion of Shal, a gene which encodes most of the A-currents in neurons (Tsunoda and Salkoff, 1995). Shal mutant neurons typically contained only the slowly inactivating DR current, $I_{\mathrm{K}}$. Figure $3 A$ shows current traces of $I_{\mathrm{K}}$ from a representative Shal mutant neuron in response to voltage jumps to potentials between $-50 \mathrm{mV}$ and $+50 \mathrm{mV}$, in $10 \mathrm{mV}$ increments. $I_{\mathrm{K}}$ in these cells activates around $-20 \mathrm{mV}$ and reaches half-activation around $-3 \mathrm{mV}$ (Fig. 4B,C). Current rise times are voltage-dependent (Table 1).

Although the genetic technique described above is the most elegant technique for removing the transient current from a cell, an independent, more conventional physiological technique could also be employed for isolating $I_{\mathrm{K}}$ in wild type neurons. This method is based on the differences in steady-state inactivation properties between $I_{\mathrm{A}}$ and $I_{\mathrm{K}}$ in neurons, which is not present in muscles. $I_{\mathrm{A}}$ in neurons (Shal) has a much more hyperpolarized steady-state inactivation curve than $I_{\mathrm{K}}$ and thus is eliminated by more negative prepulses than $I_{\mathrm{K}}$. On average, $I_{\mathrm{A}}$ was half-inactivated with a prepulse to $-75 \mathrm{mV}$, while $I_{\mathrm{K}}$ was half-inactivated with a prepulse to $-29 \mathrm{mV}$. Thus, when peak current in wild type cells is plotted versus prepulse potential, data points could usually be fit with a double Boltzmann equation, representing the two functionally independent components, $I_{\mathrm{A}}$ and $I_{\mathrm{K}}$ (Fig. $3 B$ ). We found that $100 \%$ of wild type neurons $(N=18)$ contained $I_{\mathrm{A}}$, while $78 \%$ contained both $I_{\mathrm{A}}$ and $I_{\mathrm{K}}$. When present in the same cell, the two components are sufficiently separated by their distinct voltage-operating ranges such that a prepulse to around $-50 \mathrm{mV}$ completely inactivates all transient Shal currents, leaving $I_{\mathrm{K}}$ fully active (Fig. $3 B$ ). Figure $3 B$ (top, right) shows $I_{\mathrm{K}}$ isolated in a wild type cell in this manner.

When comparing $I_{\mathrm{K}}$ in neurons isolated by the two techniques, we find that $I_{\mathrm{K}}$ isolated in Shal mutant neurons appears virtually identical to $I_{\mathrm{K}}$ isolated in wild type neurons by prepulse inactivation. Thus, the genetic removal of Shal has no effect whatsoever on $I_{\mathrm{K}}$. Figure $3 B$ (bottom, right) shows $I_{\mathrm{K}}$ isolated by each technique, in two different cells, superimposed on one another. Figure 4 compares $I_{\mathrm{K}}$ isolated by both techniques. $I_{\mathrm{K}}$ in both wild type and Shal mutant neurons activates between -30 and $-20 \mathrm{mV}$. The activation and steady-state inactivation of $I_{\mathrm{K}}$ isolated by both techniques shows a similar voltage dependence (Fig. $4 B, C$ ). In wild type neurons, $I_{\mathrm{K}}$ reaches half-activation at $-1 \mathrm{mV}(N=6)$, and is half-inactivated by a prepulse to -30 $\mathrm{mV}(N=9)$. Activation and steady-state inactivation data points from $I_{\mathrm{K}}$ in a representative Shal mutant neuron are shown superimposed on the same graphs as for $I_{\mathrm{K}}$ in wild type neurons to show the great similarity between $I_{\mathrm{K}}$ currents isolated by the two techniques.

\section{Shab encodes $\mathrm{I}_{K}$ in embryonic neurons}

Having analyzed the $I_{\mathrm{K}}$ component in neurons, we next compared its properties to $I_{\mathrm{K}}$ in muscle which we showed earlier in this study to be encoded by Shab. We found that, indeed, $I_{\mathrm{K}}$ in neurons is very similar to $I_{\mathrm{K}}$ in muscle, with respect to all properties (Table 1). Thus, we suspected that the neuronal $I_{\mathrm{K}}$ component was also encoded by Shab. This hypothesis is consistent with a previous study in Drosophila neurons which suggested that $S h a b$ encodes this DR current, a conclusion based on the similarity of single channel currents found in neurons to Shab single channel currents expressed in Xenopus oocytes (Tsunoda and Salkoff, 1995).

To determine whether Shab encodes $I_{\mathrm{K}}$ in neurons, we compared currents in wild type neurons to those in Shab mutant neurons. As in muscle, the $S h a b$ deficiency removed $I_{\mathrm{K}}$. We found that none of the Shab-deficient neurons $(N=26)$ contained the current component corresponding to $I_{\mathrm{K}}$, as described in the previous section. Shab-deficient neurons had a steadystate inactivation curve that was always fit with a single Boltzmann component characteristic of that of the Shal current, while 
A)
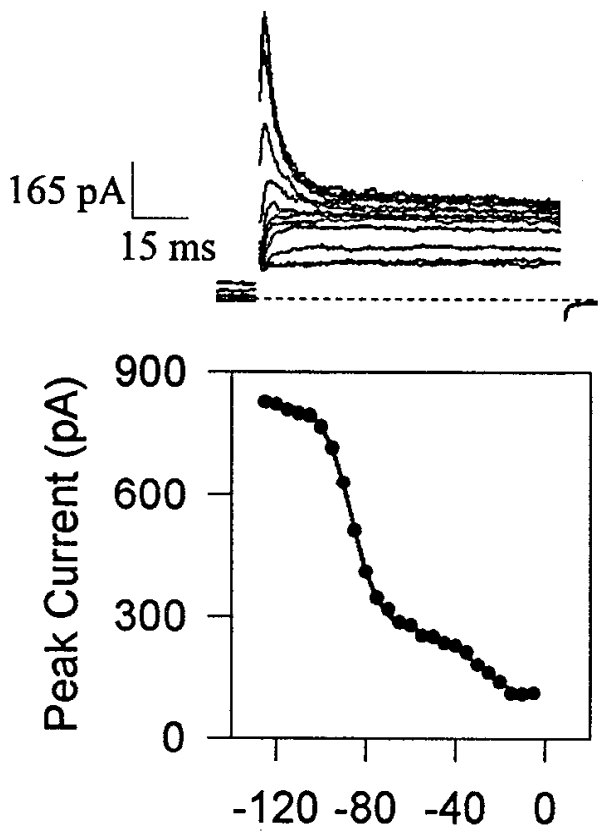

Prepulse Potential (mV)

B)
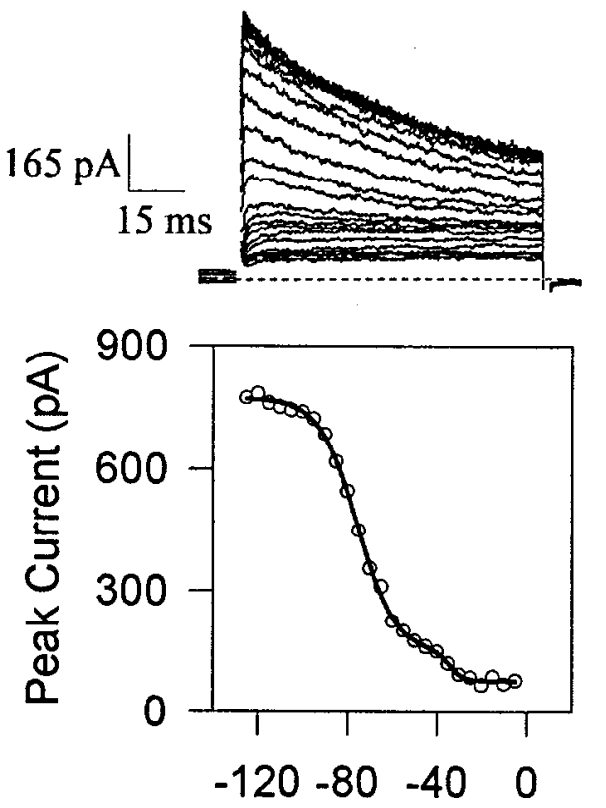

Prepulse Potential (mV)

\section{Shab Mutant}
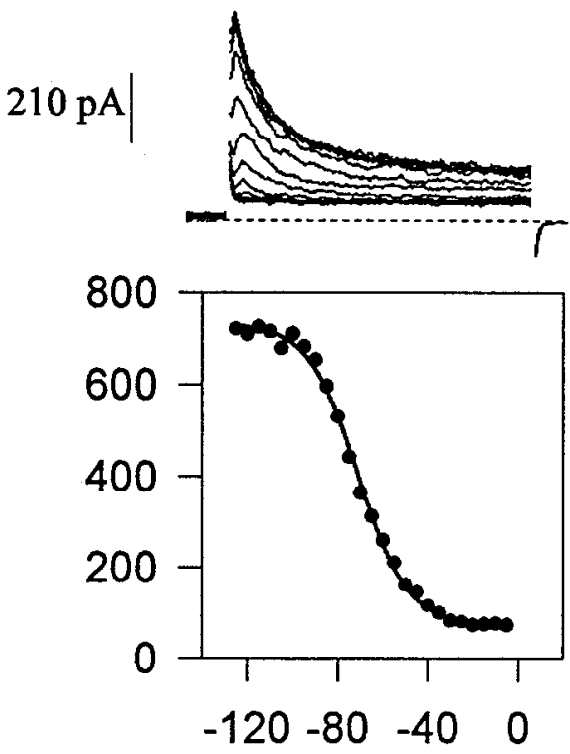

Prepulse Potential (mV)

\section{Shab Mutant}
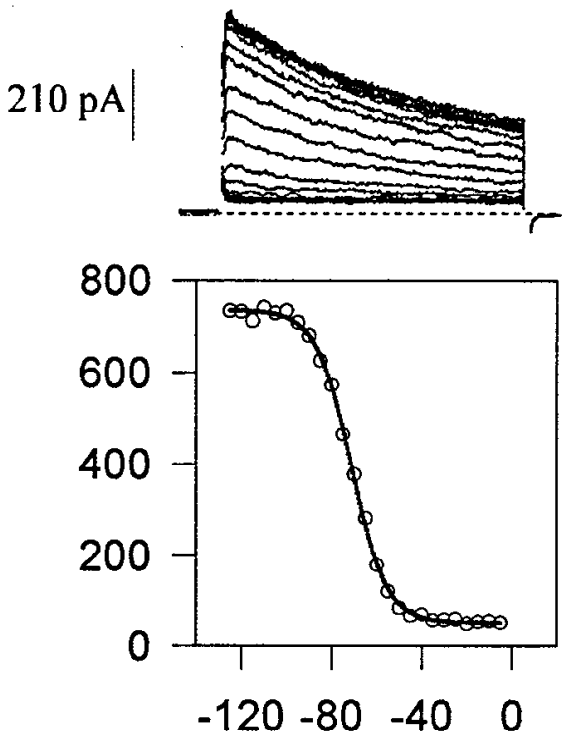

Prepulse Potential (mV)

Figure 6. Selective removal of $I_{\mathrm{K}}$ in neurons by Shab mutation. A: Left (Wild Type), fast $I_{\mathrm{A}}$, Current traces in response to a steady-state inactivation voltage paradigm from a representative wild type neuron containing a Shal current with a very fast inactivation rate. Right (Shab-Mutant), fast $I_{\mathrm{A}}$, Current traces in response to the same steady-state inactivation voltage paradigm from a representative $S h a b$-deficient neuron containing a similar fast transient Shal current. Current traces shown were in response to a test jump were to $+50 \mathrm{mV}$. Each test jump was preceded by a $500 \mathrm{msec}$ prepulse to potentials between -125 and $-5 \mathrm{mV}$, in $5 \mathrm{mV}$ increments. Traces are shown in response to prepulses every $10 \mathrm{mV}$. Bclow current traces, peak current is plotted versus prepulse potential at $5 \mathrm{mV}$ intervals. Data points are best fit with either one or the sum of two Boltzmann equations: $I=I_{\max } /\left(1+\exp \left(\left(V-V_{z_{2}}\right) / k\right)\right)+$ baseline, where $V_{1,2}$ is the potential at which current is half-inactivated, $k$ is $R T / z F$, baseline is offset current due to "leak" current and noninactivating (Shaw) currents present. Wild type currents shown were best fit with the sum of two Boltzinami equations as shown. The transient Shal current component is fit with the parameters, $I_{\max }=544.98 \mathrm{pA}, V_{1 / z}=-86.2 \mathrm{mV}, z=6.19 \mathrm{mV} / e$-fold shift; 

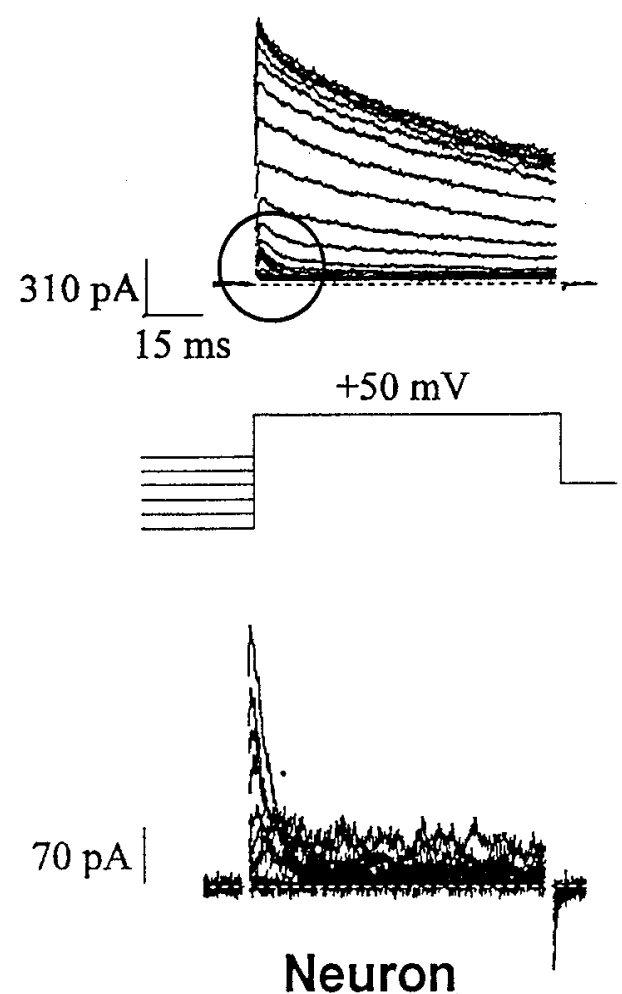
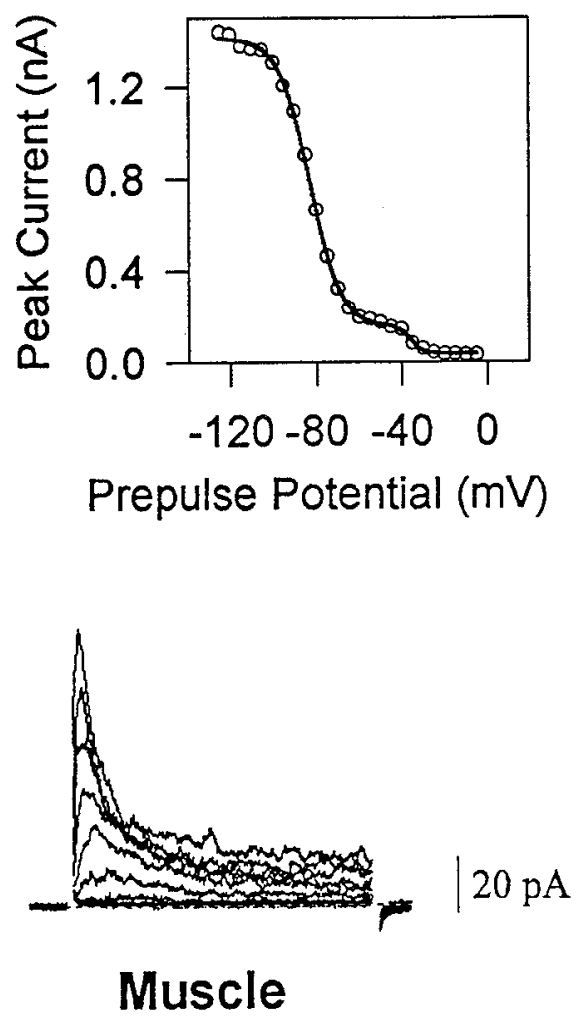

Figure 7. Shaker-like current revealed in Shab mutant neurons. Top, Current traces in response to a steady-state inactivation voltage paradigm from a Shab-deficient neuron (left). Membrane was prepulsed $(1 \mathrm{sec}$ ) to potentials between -125 and $-5 \mathrm{mV}$, in $5 \mathrm{mV}$ increments, prior to stepping to a test potential of $+50 \mathrm{mV}$ for $80 \mathrm{msec}$. Peak current is plotted versus prepulse potential (right). Unlike most Shab-deficient neurons, data points are fit with the sum of two Boltzmann equations, $I=\left(I_{\max } /\left(1+\exp \left(\left(V-V_{1_{2}}\right) / k\right)\right)\right)+\left(I_{\max 2} / 1+\exp \left(\left(V-V_{y_{2}} / k_{2}\right)\right)\right)$ as previously described, indicating two separable components. Unlike wild type neurons, both current components (left) are transient A-type currents. The larger transient component has a hyperpolarized steady-state inactivation curve characteristic of Shal currents in these neurons. Best fit parameters for this component are $I_{\max }$ $=1.3 \mathrm{nA}, V_{3 / 2}=-82.7 \mathrm{mV}, z=7.00 \mathrm{mV} / e$-fold shift. The smaller transient component has a more depolarized steady-state inactivation curve charactcristic of Shaker currents scen in muscle. Best fit parameters for this component are $I_{\max }=100 \mathrm{pA}, V_{1 / 2}=35.5 \mathrm{mV}, z=2.98 \mathrm{mV} / e$-fold shift. Bottom, Whole cell Shaker-like current in neurons (left) and Shaker current in a representative Shab-deficient myotube (right). Neuronal Shaker-like current shown is from the same cell as above. Membrane was prepulsed to $-50 \mathrm{mV}$ to inactivate the larger transient Shal current and voltage jumps were taken to potentials between -50 and $+40 \mathrm{mV}$, in $10 \mathrm{mV}$ increments. Similar voltage jumps were taken from a holding potential of $-90 \mathrm{mV}$ for the Shab-deficient myotube.

most wild type neurons $(78 \%)$ had a steady-state inactivation curve that was fit with the sum of two Boltzmann functions, one corresponding to Shal, and one corresponding to Shab, as seen in muscles. Figure 5 shows steady-state inactivation midpoints from wild type and $S h a b$-deficient neurons plotted in separate histograms. Two populations of inactivation midpoints appears to be present in wild type neurons: one hyperpolarized, averaging $-75 \mathrm{mV}$, that corresponds to $I_{\mathrm{A}}$ (Shal), and a second depolarized, averaging $-29 \mathrm{mV}$, that corresponds to $I_{\mathrm{K}}$. In contrast, only the more hyperpolarized population of inactivation midpoints, averaging $-71 \mathrm{mV}$, appears to be present in Shab-deficient neurons. Thus, the Shab deficiency eliminates the currents with a more depolarized steady-state inactivation midpoint, $I_{\mathrm{K}}$, while leaving the component corresponding to the transient Shal current unaltered.

Since Shal currents have been shown to have different rates of inactivation (Tsunoda and Salkoff, 1995), we wanted to confirm that the Shab mutation eliminates $I_{\mathrm{K}}$ regardless of the kinetics of the Shal current present. Figure 6 shows representative wild type and Shab-deficient neurons containing fast (very rapidly inactivating) and slow (less rapidly inactivating) Shal currents. Steady-state inactivation analysis reveals that $I_{\mathrm{K}}$ is eliminated with the Shab deficiency, regardless of the kinetics of the Shal current $\left(I_{\mathrm{A}}\right)$. Thus, we conclude that Shab encodes $I_{\mathrm{K}}$ in

$\leftarrow$

the slowly inactivating current component $I_{\mathrm{k}}$ is fit with the parameters, $I_{\max }=180.48 \mathrm{pA}, V_{1 / \mathrm{z}}=-30.0 \mathrm{mV}, z=9.31 \mathrm{mV} / e$-fold shift, baseline $=$ $91.69 \mathrm{pA}$. In contrast, the $S h a b$-deficient neuron was fit with only a single Boltzmann equation with the following parameters for the transient Shal current: $I_{\max }=655.55 \mathrm{pA}, V_{3 / 2}=-71.0 \mathrm{mV}, z=10.94 \mathrm{mV} / e$-fold shift, baseline $=74.75 \mathrm{pA}$. B: Left (Wild Type), slow $I_{\mathrm{A}}$, Current traces in response the same a steady-state inactivation voltage paradigm from a representative wild type neuron containing a Shal current with a slower inactivation rate. Right (Shab-Mutant), slow $I_{\mathrm{A}}$, Current traces in response the same steady-state inactivation voltage paradigm from a representative $S h a b$-deficient neuron containing a Shal current similar to the one of the wild type neuron shown. Steady-state inactivation curve from the wild type neuron is best fit with a double Boltzmann equation while the steady-state inactivation curve from the Shab-deficient neuron is best fit with a single Boltzmann equation. For the wild type neuron, the transient Shal current component, best fit parameters are $I_{\max }=624.59 \mathrm{pA}, V_{2 / 2}=-75.4$ $\mathrm{mV}, z=8.50 \mathrm{mV} / e$-fold shift; the slowly inactivating current component $I_{\mathrm{K}}$ has best fit parameters of $I_{\max }=72.64 \mathrm{pA}, V_{1 / 2}=-34.1 \mathrm{mV}, k=3.08$ $\mathrm{mV} / e$-fold shift, baseline $=75.68 \mathrm{pA}$. For the Shab-deficient neuron, the transient Shal current component is best fit the parameters $I_{\max }=682.47$ $\mathrm{pA}, V_{1 / 2}=-71.1 \mathrm{mV}, z=7.77 \mathrm{mV} / e$-fold shift, baseline $=51.71 \mathrm{pA}$. 
neurons as well as in muscle, and that the Shab encoded component is completely independent of the transient component in the cell.

\section{Shaker revealed in Shab mutant neurons}

Although the predominant A-current in embryonic neurons is encoded by Shal, previous work has suggested that Shaker might also encode an A-current in a small percentage of pupal neurons (Baker and Salkoff, 1990). However, it was not apparent that any wild type neurons in our preparation derived from the late embryo contained two separable A-currents. Nevertheless, $I_{\mathrm{K}}$ was eliminated with a genetic deficiency of Shab, two transient currents became apparent in a small percentage of cells. In most Shab-deficient neurons, only the transient Shal current, with its characteristically hyperpolarized steady state inactivation curve, was present, but in $11 \%$ of the Shab-deficient neurons $(N=26)$, two A-currents were observed. These two components had distinct voltage-operating ranges; steady-state inactivation curves were fit with a double Boltzmann function, corresponding to one transient current with a hyperpolarized steady-state inactivation curve, and a second transient current with a depolarized steadystate inactivation curve (Fig. 7). The larger of the two components always had a hyperpolarized steady-state inactivation curve, characteristic of Shal currents. The smaller component had a steady-state inactivation midpoint of about $-35 \mathrm{mV}$, which was unlike Shal (Tsunoda and Salkoff, 1995), but quite similar to Shaker (Solc et al., 1987; Baker and Salkoff, 1990).

The reason that this second component was difficult to detect became apparent when it was realized that it had a steady-state inactivation curve very similar to that of the Shab DR current (Figs. 4, 5). Thus, the small A-current was masked by the larger DR Shab current in experiments designed to separate components based on differences in steady-state inactivation properties. Thus, its presence could only be detected when the Shab current was eliminated.

The steady-state inactivation midpoint of this small A-current $(-35 \mathrm{mV})$ is similar to that of Shaker currents in embryonic myotubes, which have a $V_{15}$ of $30 \mathrm{mV}$ (Solc et al., 1987). To isolate and examine this A-current in neurons, we inactivated the large Shal current with a prepulse to $-50 \mathrm{mV}$ and took voltage jumps to potentials between -50 and $+40 \mathrm{mV}$, in 10 $\mathrm{mV}$ increments. This A-current was not activated until potentials of $-20 \mathrm{mV}$ and above, another property similar to Shaker currents in other cell types (Salkoff, 1983b; Wu and Haugland, 1985; Solc et al., 1987; Broadie and Bate, 1993). This is markedly unlike Shal currents which activate between -50 and -40 $\mathrm{mV}$ (Tsunoda and Salkoff, 1995). This small A-current also had activation kinetics and inactivation rates that were similarly voltage-dependent to Shaker currents in other cell types (data not shown). Figure 7 compares this Shaker-like current to Shaker currents observed in Shab-deficient myotubes. Because this Shaker-like current is present in such a small percentage of Shab-deficient neurons, the verification by mutant analysis that this current was encoded by the Shaker genc was not practical. However, because of its great similarity to Shaker currents observed in muscle cells, we suggest the likelihood that it is.

\section{Shaw encodes a small steady-state current in both neurons} and muscle

In neurons, we previously found that Shaw encodes a noninaclivating $\mathrm{K}^{+}$channel with distinclive properties, which include an unusually low voltage sensitivity, a short mean open time, and a large conductance (Tsunoda and Salkoff, 1995). These single channel properties give rise to a whole cell current which behaves much like a small, leak-type current in neurons. Since Shab appears to encode most, but not quite all, of the DR current in myotubes, we suspected that Shaw might be responsible for the remaining steady-state current in myotubes, as it is in neurons.

We found that myotubes do indeed contain a channel that is very similar in conductance and behavior to the Shaw channels identified in neurons. Figure 8 shows representative records of Shaw channels in neurons compared to the Shaw-like channels observed in myotubes. Shaw-like channels in myotubes, like neuronal Shaw channels, also appear to have brief open times and a low voltage sensitivity. Current-voltage relations, revealed by single channel activity during a voltage ramp (Fig. 8), predict a similar large conductance of Shaw channels in myotubes as well as neurons: $62 \mathrm{pS}$ in myotubes, and $48 \mathrm{pS}$ in neurons. Thus, Shaw appears to be responsible for a small steady-state current that remains in Shab-deficient myotubes.

\section{Discussion}

The same gene, Shab, encodes the major delayed rectifier current in Drosophila neurons and muscle

Historically, voltage-dependent $\mathrm{K}^{+}$currents have been generally classified as either a transient A-type current or a delayed rectifier (DR) type current (review by Rudy, 1988: Hille, 1992). However, although DR currents in both neurons and muscle cells have been described, the genetic identity of these currents is rarely known unambiguously. Previous studies in Drosophila have identified $I_{\mathrm{K}}$ and $I_{\mathrm{A}}$ current components, but their genetic identity was not determined (Byerly and Leung, 1988; Saito and Wu, 1993). Here we show by mutant analysis that the major DR current in both Drosophila neurons and muscle is encoded by the same gene, $S h a b$, and that $S h a b$ appears to be virtually the exclusive gene encoding DR currents. It is possible that mammalian Shab genes play a similarly important role. Although numerous mammalian Shaker homologs express DR-type currents in the Xenopus oocyte expression system, there is little evidence that they actually have similar kinetics in mammalian neurons.

\section{Genetic and functional independence of the major delayed rectifier current in Drosophila}

We have found that although multiple $\mathrm{K}^{\prime}$ channel genes are expressed at the same time, and in the same cells of Drosophila neurons and muscles, $\mathrm{K}^{+}$currents, such as $I_{\mathrm{K}}$ and $I_{\mathrm{A}}$, appear to be genetically, as well as functionally, independent of one another. This concept of independent $\mathrm{K}^{+}$current systems was originally suggested in a previous report (Covarrubias et al., 1991). Subunits from all the subfamilies of cloned $\mathrm{K}^{+}$channel genes (Shaker, Shal, Shab, Shaw) form homomultimers, but Covarrubias et al. showed that there is a "barrier" to the formation of hetcromultimers from subunits cncoded by members of different subfamilies. For instance, coexpression of Shab and Shaker in Xenopus oocytes results in two separate currents expressed by Shab and Shaker homomultimers, rather than a current carried by a heteromultimeric channel containing mixtures of Shab and Shaker subunits. Consistent with these results, we find that the major DR current in both neurons and muscle is encoded by a single gene, Shab, and that it is undfected by the expression of other $\mathrm{K}^{+}$channel genes. These results should not be confused 


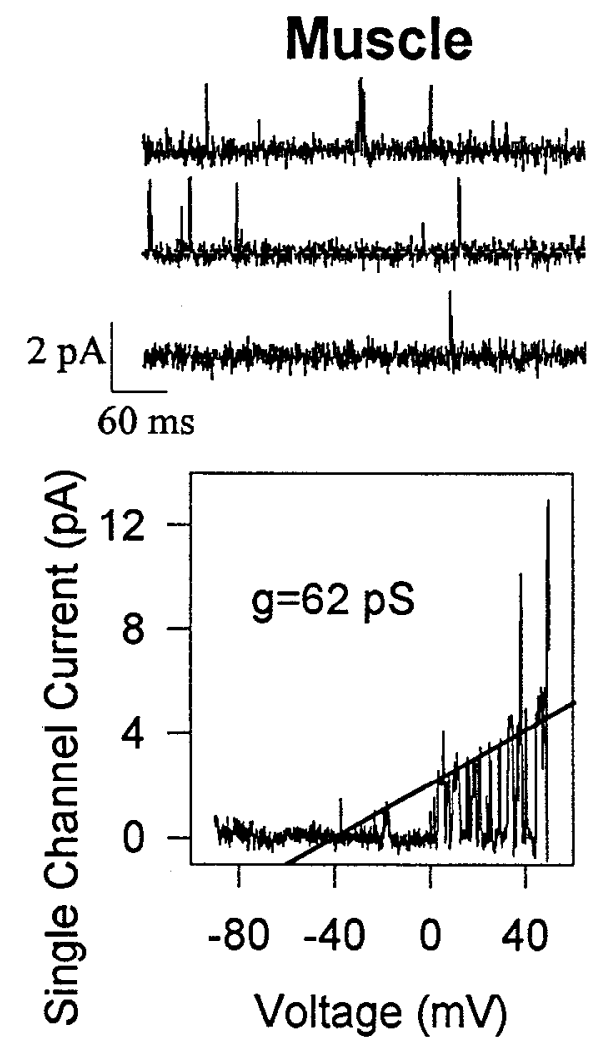

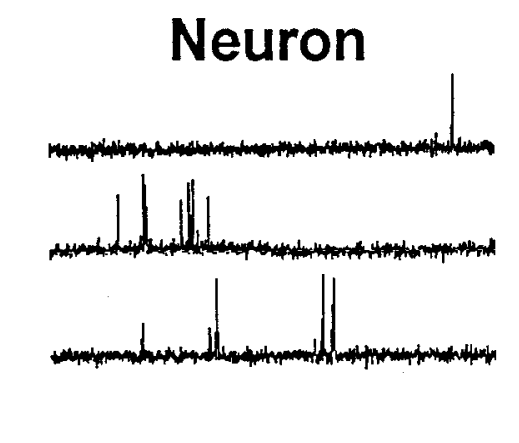

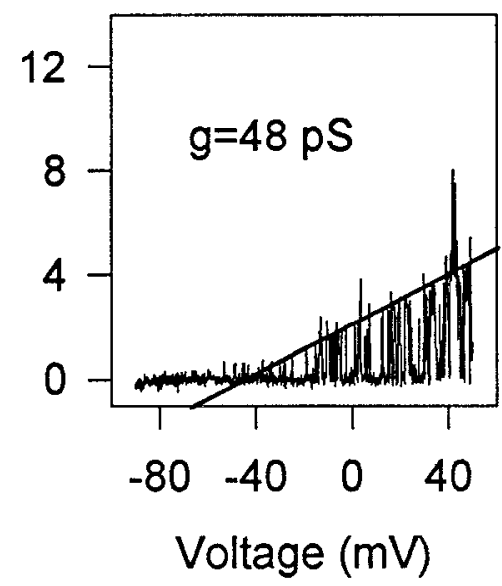

Figure 8. Shaw channels in neurons and muscle. Top, Representative traces of Shaw-like channels present in myotube (left) and identified Shaw channels in neurons (right) in outside-out patches. Traces are in response to voltage jumps to $0 \mathrm{mV}$ from a holding potential of $-60 \mathrm{mV}$. Bottom, Channel openings in response to a voltage ramp from $-90 \mathrm{mV}$ to $+50 \mathrm{mV}$. A line drawn by eye through channel openings predicts a conductance of $48 \mathrm{pS}$ for Shaw channels in neurons and 62 $\mathrm{pS}$ for the Shaw-like channels in myotubes. Data was digitized at 0.488 $\mathrm{msec} / \mathrm{pt}$ and filtered at $2 \mathrm{kHz}$. with the results of Sheng et al. (1993) and Wang et al. (1993), which showed that, in mammals, subunits encoded by members of the same subfamily do form heteromultimers.

Drosophila provides unique genetic tools with which to study the multiple $\mathrm{K}^{+}$currents present in Drosophila cells. The fact that a particular DR current is eliminated with a deficiency of $S h a b$ suggests that the Shab gene encodes the essential subunit of the channel that carries this current. Furthermore, the fact that deficiencies of other $\mathrm{K}^{+}$channel genes, such as Shal in neurons (Tsunoda and Salkoff, 1995) and Shaker in muscle (Salkoff and Wyman, 1981; Broadie and Bate, 1983; Salkoff, 1985; Wu and Haugland, 1985; Zagotta et al., 1988), do not affect this same DK current suggests that none of these other $\mathrm{K}^{+}$channel genes contribute subunits to the channel that carries this current. Thus, the diversity of voltage-dependent $\mathrm{K}^{+}$currents in Drosophila neurons and muscle appears to be largely explained by the combination of currents which are genetically and functionally independent.

\section{Shaw encodes a "leak"-like current in neurons and muscle}

Shaw encodes a current with similar distinctive properties in both neurons and muscle. In previous studies we showed that Shaw channels in neurons have a very low open probability and an unusually low voltage sensitivity (Baker, 1992; Tsunoda and Salkoff, 1995), and we suggested that they contribute a macroscopic current that probably functions much like a "leak" current in neurons. This small whole cell current component is sometimes detectable in Shab-deficient neurons when the predominant Shal current is inactivated. In the present study, we find that channels very similar to Shaw channels in neurons, are also present in muscle. Thus, while $S h a b$ encodes the major DR current in both neurons and muscle, Shaw appears to encode a minor leak-type current in both cell types. Since Northern analysis suggests that Shaw has only one splice form which is ex- pressed throughout development and into adulthood (Tsunoda and Salkoff, 1995), Shaw may play the role of a leak-type channel in multiple cell types throughout development.

\section{A genetically defined system}

Many $\mathrm{K}^{+}$channel genes from Drosophila and mammals have been characterized in heterologous expression systems. However, little is known about the currents which are expressed by these genes in their normal cells. Northern analysis and even PCR amplification of channel genes from identified tissues, or even single cells, can only provide a correlation of gene expression with electrophysiology, rather than a certainty of which gene expresses which current. In this study and in recent work (Tsunoda and Salkoff, 1995), we use unique genetic tools only available in Drosophila to examine native $\mathrm{K}^{+}$currents in wild type cells and cells which contain genetic deficiencies for each of the known $\mathrm{K}^{+}$channel genes cloned in Drosophila. In this way, we can unambiguously identify the currents of the cloned $\mathrm{K}^{+}$channel genes in their native cells.

Shaker currents were the first ion currents to be genetically characterized. Shaker was shown to encode the A-type current in muscle at developmental stages from the embryo to the adult (Salkoff and Wyman, 1981; Broadie and Bate, 1983; Salkoff, 1983; Salkoff, 1985; Wu and Haugland, 1985; Solc et al., 1987; Zagotta et al., 1988). More recently, we showed that the A-type currents in the soma of neurons are encoded by the Shal gene (Tsunoda and Salkoff, 1995). Now, in our current study, we show that, in both neurons and muscle, the major delayed rectifier current is encoded by Shab, while a minor, noninactivating current is probably encoded by Shaw. Thus, all of the major whole cell current components can be genetically assigned to each of the cloned genes, Shaker, Shal, Shab, and Shaw, perhaps suggesting that the "set" of genes encoding voltage-dependent $\mathrm{K}^{+}$currents is virtually complete. 
At the single channel level, virtually all currents, in both neurons and muscle, can now be assigned to each of the cloned genes from Drosophila. In neurons, we previously showed that only three types of single channel currents are apparent at the cell soma of embryonic neurons. Two of these single channel currents were shown by mutant analysis to be encoded by Shal and Shaw (Tsunoda and Salkoff, 1995). A third single channel current, similar to single Drosophila Shab channels heterologously expressed in Xenopus oocytes (Tsunoda and Salkoff, 1995), was assumed to underlic the slowly inactivating DR current, $I_{\mathrm{K}}$. In this study, we show that $I_{\mathrm{K}}$ is indeed encoded by Shab. Thus, all the single channel currents in embryonic neurons can now be accounted for. In a previous study, similar single $\mathrm{K}^{+}$ channel currents were observed in larval neurons (Solc and Aldrich, 1988). Although these currents were not identified genetically, their similarity to the identified channels in embryonic neurons make it likely that they are expressed by Shal, Shaw, and Shab.

In muscle, most single channel currents can also be accounted for by the cloned genes. Of the four types of single channel currents that have been described by Zagotta et al. (1988), three are voltage dependent. The first, $\mathrm{A}_{1}$, is rapidly inactivating and was shown to be encoded by Shaker (Zagotta et al., 1988). The second, called the $K_{D}$ channcl, has properties of a delayed rectifier current, $I_{\mathrm{K}}$, which we believe underlies the whole cell current shown in our study to be encoded by Shab. In addition, consistent with our study, $\mathrm{K}_{\mathrm{D}}$ channels were observed in both neurons and muscle (Zagotta et al., 1988; Solc and Aldrich, 1990), just as we find that whole cell Shab currents are present in both neurons and muscle. The third voltage-dependent $\mathrm{K}^{+}$ channel described by Zagotta et al. (1988) is the $\mathrm{K}_{\mathrm{o}}$ channel, which we suggest is encoded by Shaw, based on its similarity to Shaw channels previously identified in neurons (Tsunoda and Salkoff, 1995). From Drosophila, we now have a unique culture system in which to study native ion channels in a system that is almost completely genetically defined.

Voltage-dependent $\mathrm{K}^{+}$channels in Drosophila have now been studied at multiple levels, the results of which all contribute to a consistent picture. The delayed rectifier currents in neurons and muscle are encoded by the only two cloned $K$ channel genes in Drosophila which express currents with delayed rectifier type properties in the Xenopus oocyte expression system, Shab and Shaw. The transient A-type currents observed in Drosophila neurons and muscle are encoded by Shal and Shaker, respectively, the only two cloned Drosophila genes which express A-type currents in Xenopus oocytes. Each gene appears to express a current which is independent from all the others. And finally, all of the voltage-dependent $\mathrm{K}^{+}$currents present in Drosophila neurons and muscle can be accounted for by these four genes alone.

\section{References}

Bader CR, Bertrand D, Dupin E (1985) Voltagc-dependent potassium currents in developing neurones from quail mesencephalic neural crest. J Physiol (Lond) 366:129-151.

Baker K (1992) Diversity of $\mathrm{K}^{+}$currents expressed by a gene family conserved in Drosophila and mouse. PhD thesis, Washington University.

Baker K, Salkoff L (1990) The Drosophila Shaker gene codes for a distinctive $\mathrm{K}^{+}$current in a subset of neurons. Neuron 2:129-140.

Butler A, Wei A, Baker K, Salkoff L (1989) A family of putative potassium channel genes in Drosophila. Science 243:943-947.

Broadie KS, Bate M (1993) Development of larval muscle properties in the embryonic myotubes of Drosophila melanogaster. J Neurosci 13:167-180.

Byerly L, Liung H-T (1988) Ionic currents of Drosophila neurons in embryonic cultures. J Ncurosci 8:4379-4393.

Covarrubias M, Wei A, Salkoff L (1991) Shaker, Shal, Shab, and Shaw express independent $\mathrm{K}^{+}$current systems. Neuron 7:763-73.

Frech GC, VanDogen AMJ, Schuster G, Brown AM, Joho RH (1989) A novel potassium channel with delayed rectifier properties isolated from rat brain by expression cloning. Nature 340:642-645.

Gisselmann G, Sewing S, Madsen BW, Mallart A, Angaut-Petit D, Muller-Holtkamp F, Ferrus A, Pongs O (1989) The interference of truncated with normal potassium channel subunits leads to abnormal behaviour in transgenic Drosophila melanogaster. EMBO J 8:2359-64.

Hamill OP, Neher ME, Sakmann B, Sigworth FJ (1981) Improved patch-clamp techniques for high-resolution current recording from cells and cell-free membrane patches. Pfluegers Arch 391:85-100.

Hardie RC, Voss D, Pongs O, Laughlin SB (1991) Novel potassium channels encoded by the Shaker gene in Drosophila photoreceptors. Neuron 6:477-486.

Hille B (1992) Ionic channels of excitable membranes. Sunderland, MA: Sinauer

Hodgkin AL, Huxley AF (1952) Currents carried by sodium and potassium ions through the membrane of the giant axon of Loligo. J Physiol (Lond) 116:449-472.

Hwang PM, Glatt CE, Bredt DS, Yellen G, Snyder SH (1992) A novel $\mathrm{K}^{+}$channel with unique localizations in manmalian brain: molecular cloning and characterization. Neuron 8:473-481.

Hwang PM, Fotuhi M, Bredt DS, Cunningham AM, Snyder SH (1993a) Contrasting immunohistochemical localizations in rat brain of two novel $\mathrm{K}^{+}$channels of the Shab subfamily. J Neurosci 13:1569-1576.

Hwang PM, Cunningham AM, Peng YW, Snyder SH (1993b) CDRK and DRK $1 \mathrm{~K}^{+}$channels have contrasting localizations in sensory systems. Neuroscience 55:613-620.

Jan LY, Jan Y-N (1982) Antibodies to horseradish peroxidase as spe cific neuronal markers in Drosophila and in grasshopper embryos. Proc Natl Acad Sci USA 79:2700-2704.

Lindsley DL, Zimm GG (1992) The genome of Drosophila melanogaster. San Diego: Academic.

Marty A, Neher E (1983) Tight-seal whole-cell recording. In: Singlechannel recording (Sakmann B, Neher E, eds). New York: Plenum.

Pak MD, Covarrubias M, Ratcliffe A, Salkoff L (1991) A Mouse brain homolog of the Drosophila Shab $\mathrm{K}^{+}$channel with conserved delayedrectifier properties. J Neurosci 11:869-880.

Rudy B (1988) Diversity and ubiquity of $\mathrm{K}^{+}$channels. Neuroscience 25:729-749.

Saito M, Wu C-F (1993) Ionic channels in cultured Drosophila neurons. EXS 63:366-389.

Salkoff L (1983) Drosophila mutants reveal two components of fast outward current. Nature 302:249-251.

Salkoff $\mathcal{L}$ (1985) Development of ion channels in the flight muscles of Drosophila. J Physiol (Lond) 80:275-282.

Salkoff L, Wyman R (1981) Genetic modification of potassium channels in Drosophila Shaker mutants. Nature 293:228-230

Seecof RL, Donady JJ (1972) Factors affecting Drosophila neuron and myocyte differentiation in vitro. Mech Age Dev 1:165-174.

Scccof RL, Alleaume N, Teplitz RL, Gerson I (1971) Differentiation of neurons and myocytes in cell cultures made from Drosophila gastrulae. Exp Cell Res 69:161-173.

Sheng M, Liao YJ, Jan YN, Jan LY (1993) Presynaptic A-current based on heteromultimeric $\mathrm{K}^{+}$channels detected in vivo. Nature 365:72 75.

Shields G, Sang JH (1970) Characteristics of five cell types appearing during in vitro culture of embryonic material from Drosophila melanogaster. J Embryol Exp Morphol 23:53-69.

Solc CK, Aldrich RW (1988) Voltage-gated potassium channels in larval CNS neurons of Drosophila. J Neurosci 8:2556-2570.

Solc CK, Zagotta WN, Aldrich RW (1987) Single-channel and genetic analyses reveal two distinct A-type potassium channels in Drosophila. Science 236:1094-1098.

Thompson S (1982) Aminopyridine block of transient potassium current. J Gen Physiol 80:1-18.

Trimmer JS (1991) Immunological identification and characterization of a delayed rectifier $\mathrm{K}^{+}$channel polypeptide in rat brain. Proc Natl Acad Sci USA 88:10764-10768. 
Trimmer JS (1993) Expression of Kv2.1 delayed rectifier $\mathrm{K}^{+}$channel isoforms in the developing rat brain. FEBS Lett 324:205-210.

Tsunoda S, Salkoff L (1995) Genetic analysis of Drosophila neurons: Shal, Shaw and Shab encode most embryonic potassium currents. J Neurosci 15:1741-1754.

Wang H, Kunkel DD, Martin TM, Schwartzkroin PA, Tempel BL (1993) Heteromultimeric $\mathrm{K}^{+}$channels in terminal and juxtaparanodal regions of neurons. Nature 365:75-79.

Wei A, Covarrubias M, Butler A, Baker K, Pak M, Salkoff L (1990)
$\mathrm{K}^{+}$current diversity is produced by an extended gene family conserved in Drosophila and mouse. Science 248:599-603.

Wohlwill AD, Bonner JJ (1991) Genetic analysis of chromosome region 63 of Drosophila melanogaster. Genetics 128:763-775.

Wu C-F, Haugland FN (1985) Voltage clamp analysis of membrane currents in larval muscle fibers of Drosophila: alteration of K currents in Shaker mutants. J Neurosci 5:2626-2640.

Zagotta WN, Brainard MS, Aldrich RW (1988) Single-channel analysis of four distinct classes of potassium channels in Drosophila muscle. J Neurosci 8:4765-4779. 